\title{
A Study of Liquid Sloshing in an Automotive Fuel Tank under Uniform Acceleration
}

\author{
Rajamani Rajagounder*, Guru Vignesh Mohanasundaram, and Prakasan Kalakkath \\ Department of Production Engineering, PSG College of Technology, Coimbatore - 641 004, India \\ *E-mail: rajamani.vrr@gmail.com
}

\begin{abstract}
This paper presents the free surface behaviour of liquid in a partially filled automotive fuel tank under uniformly accelerated motion. The liquid in the fuel tank is subjected to violent sloshing during sudden acceleration or stopping of the vehicle which will produce structural vibration and noise in the passenger compartment. To reduce this sloshing, baffles are used inside the tank. The objective of this work is to study the influence of vertical baffles and fill levels on free surface elevation of liquid in a partially filled fuel tank. The simulation of liquid free surface behaviour under uniform acceleration is done using ANSYS-FLUENT software. A numerical model is developed based on Volume of Fluid (VOF) technique to track the free surface motion of liquid. The explicit time discretization scheme is employed to solve the volume fraction equation. From the numerical analysis, amplitude of free surface elevation and slope of free surface are predicted. Experiments are carried out with transparent fuel tank, fabricated using glass fibre and epoxy resin. A uniform acceleration is applied to the tank and free surface displacements of liquid are captured using high speed camera. Also, an analytical model is formulated to find position of the free surface of liquid in a rectangular container subjected to uniform acceleration. The free surface profiles obtained from the simulations are compared with the experimental results.
\end{abstract}

Keywords: Liquid sloshing, volume of fluid, similitude relations, free surface elevation.

ENGINEERING JOURNAL Volume 20 Issue 1

Received 6 March 2015

Accepted 26 June 2015

Published 29 January 2016

Online at http://www.engj.org/

DOI:10.4186/ej.2016.20.1.71 


\section{Introduction}

The free surface motion of the liquid in a partially filled container due to external excitation is called liquid sloshing. Liquid sloshing finds wide range of applications in engineering fields such as design of automotive fuel tanks, containers for transporting liquid on highways, ships and space vehicles, seismically excited storage tanks, dams, and nuclear reactors. Sloshing creates highly localized impact pressure on the walls that may in turn cause structural damage and also sufficient moment to affect the stability of the vehicle which carries the liquid container. The amplitude of the free surface motion of liquid depends on the type of motion, amplitude and frequency of excitation, tank geometry, fill levels and liquid properties [1]. Thus, sloshing phenomena and associated structural behavior are analyzed while designing containers for liquid storage and transportation.

Sloshing in a fuel tank normally occurs during hard acceleration, cornering, braking of the vehicle and travelling in rough terrain. The behaviour of liquid in a fuel tank has to be studied in order to minimize the fuel sloshing inside the tank. This fuel sloshing in an automotive fuel tank leads to the problem of acoustic noise in the passenger compartment, structural vibrations, low fuel level management and excess fuel vapour formation in case of gasoline fuel systems. Understanding the liquid free surface motion in a partially filled tank could support the designer to minimize the sloshing at the beginning of the design process itself. Hence, this study is carried out to analyse the sloshing behaviour of liquid in the partially filled automotive fuel tank.

Prediction of the free surface motion of liquid has received great interest among researchers over the last few decades and some of the studies on liquid sloshing are presented. Francis and Eddie [2], developed a marker and cell method (MAC) based on finite difference approach to study the dynamics of an incompressible fluid with free surface. Hirt and Nichols[3], presented fractional volume of fluid (VOF) technique for tracking complex free surface motion of incompressible fluid. Abramson [4] and Ibrahim [5] presented a comprehensive review and discussion of the analytical, numerical and experimental studies carried out on liquid sloshing in rectangular, cylindrical, elliptical and spherical containers. Thomas et al. [6] employed a mixed Lagrangian-Eulerian formulation for modeling the fluid domain of free-surface of liquid and fluid-structure interaction problems.

Subhash Babu and Bhattacharyya [7] developed an algorithm using finite element technique for predicting the sloshing displacement and the pressure developed in a liquid filled container due to sloshing. Pal et al. [8] performed an experimental analysis of liquid sloshing in a cylindrical container with and without baffles. The experimental results are supported with Galerkin's finite element formulation based numerical analysis.

Aquelet et al. [9] developed a numerical model based on Arbitrary Lagrangian-Eulerian approach to predict the natural frequency of fuel tank with various baffle configurations. Dongming Liu and Pengzhi Lin [10] developed a numerical model called NEWTANK to study three-dimensional nonlinear liquid sloshing with broken free surfaces. In their numerical model, the second-order accurate volume-of-fluid method is used to track the distorted and broken free surface. Popov et al. [11] investigated the effect of acceleration and curvature on the fluid motion in rectangular containers and observed that the most intense sloshing occurs when the fill level is approximately $30-60 \%$.

Stefen aus der Wiesche [12] developed virtual slosh tool based on VOF approach to predict sloshing behavior of liquid in an automotive fuel tank. The study reports the effect of viscosity on damping rate and influence of fill levels on natural frequency of the automotive fuel tank. Stefan aus der Wiesche [13] experimentally analyzed noise due to sloshing in the automotive fuel tanks and established a correlation between recorded slosh noise and simulated pressure fluctuations within the sloshing liquid. A similar study was performed by Wachowsk et al., [14] a special test rig with acoustic camera was developed to detect the slosh noise in the automotive fuel tank and experimental results are compared with the pressure fluctuations obtained by numerical simulations.

Eswaran et al.[15] experimentally studied the effects of excitation amplitude, frequency and liquid fill level on free surface elevation of liquid in rectangle container. Heng Jin et al. [16] conducted detailed studies on liquid motions in a rectangular tank with an inner submerged horizontal perforated plate and reported that perforated plate placed under the water surface could significantly reduce the sloshing wave amplitude. Eswaran et al. [17] used volume of fluid techniques with ALE formulation to investigate the effect of vertical, horizontal baffles and a ring baffle on the free surface motion in rectangle tank.

Jung et al. [18] numerically investigated the effect of a vertical baffle on liquid sloshing in a three dimensional rectangular tank using the VOF formation. Recently, C. Koh et al. [19] used the constrained 
floating baffle (CFB) in prismatic tank and reported that $\mathrm{CFB}$ performs better than the fixed baffles. Nicolici and Bilegan [20] analysed the sloshing phenomena in a cylindrical tank with torispherical heads and predicted the sloshing wave amplitude, convective mode frequency and pressure exerted on the walls by applying the time history of an earthquake excitation.

From the literature review, it is noticed that most of the numerical and experimental analysis on free surface motion of liquid were carried out for rectangular, cylindrical and spherical containers and a very few studies report the sloshing phenomena in the automotive fuel tank and acoustic noise due to sloshing. Hence, there is a need to understand the free surface motion of liquid in the fuel tanks with intricate shape. In this work, a numerical model is developed to study the influence of baffles and liquid fill levels on the free surface motion. The numerical model is supported with analytical solution and experimental results.

The contents of the paper are organized as follows. In Section 2, analytical solution to find the position of liquid free surface in an automotive fuel is described. Section 3 presents the numerical technique used for prediction of free surface motion. Experimental setup and similitude relations used for the analysis are explained in section 4 . The results of the numerical simulations, experimental study and analytical solutions are given in Section 5. Section 6 summarizes the conclusions of this work.

\section{Analytical Solution for Free Surface Motion Of Liquid in a Rectangular Container}

The equations of motion describing the behaviour of an incompressible, immiscible two-fluid system inside a rigid rectangular tank are governed by the continuity equation and the momentum conversation equations as follows [21];

$$
\begin{gathered}
\nabla \cdot \mathrm{v}=\mathrm{O} \\
\rho\left(\frac{\partial \mathrm{v}}{\partial \mathrm{t}}+\mathrm{v} \cdot \nabla \mathrm{v}\right)=-\nabla \mathrm{P}+\rho \mathrm{g}+\mu \nabla^{2} \mathrm{v}
\end{gathered}
$$

where $\mathbf{V}$ is the fluid velocity $(\mathrm{m} / \mathrm{s}), P$ is the fluid pressure $\left(\mathrm{N} / \mathrm{m}^{2}\right), \rho$ is the fluid density $\left(\mathrm{kg} / \mathrm{m}^{3}\right), \mu$ is the viscosity of the fluid $\left(\mathrm{Ns} / \mathrm{m}^{2}\right)$ and $\mathrm{g}$ is the acceleration due to gravity $\left(\mathrm{m} / \mathrm{s}^{2}\right)$.

When the liquid container is subjected to constant acceleration, each element of the fluid in the container experiences the same acceleration; thus fluid velocity $\mathrm{v}$ is the function of time but not position. Therefore, Eq. (2) can be written as

$$
\rho \frac{D v}{D t}=-\nabla P+\rho g+\mu \nabla^{2} v
$$

where $\mathrm{D} / \mathrm{Dt}$ is the substantial derivative.

For uniformly accelerated flow,

and

$$
\begin{gathered}
\rho \frac{D v}{D t}=a, \text { a constant vector } \\
\nabla^{2} v=0
\end{gathered}
$$

Thus Eq. (3) reduces to

$$
\begin{gathered}
\rho a=-\nabla P+\rho g \\
\nabla P=\rho(g-a)
\end{gathered}
$$

Equation (7) can be written by

$$
\begin{aligned}
& \frac{\partial P}{\partial x}=\rho i(g-a) \\
& \frac{\partial P}{\partial y}=\rho j(g-a) \\
& \frac{\partial P}{\partial z}=\rho k(g-a)
\end{aligned}
$$

The total differential of the pressure is

$$
d P=\frac{\partial P}{\partial x} d x+\frac{\partial P}{\partial y} d y+\frac{\partial P}{\partial z} d z
$$

Substituting Eq. (8), Eq. (9) and Eq. (10) into Eq. (11): 


$$
d P=\rho[i \cdot(g-a) d x+j \cdot(g-a) d y+k \cdot(g-a) d z]
$$

where $i, j$ and $k$ are unit vectors.

Integrating Eq. (12) between $x_{0}, y_{0}, z_{0}$ and any arbitrary point $\mathrm{x}, \mathrm{y}, \mathrm{z}$ gives the general expression for the pressure in a uniformly accelerated fluid.

$$
P-P_{0}=\rho\left[A_{x}\left(x-x_{0}\right)+A_{y}\left(y-y_{0}\right)+A_{z}\left(z-z_{0}\right)\right]
$$

where $P=P(x, y, z), P_{o}=P\left(x_{o}, y_{o}, z_{0}\right), A_{x}=i \cdot(g-a), A_{y}=j \cdot(g-a)$ and $A_{z}=k \cdot(g-a)$.

If $x_{o}, y_{o}, z_{o}$ is a point on the free surface where the pressure is $P_{o}$ and $z=z_{s}(x, y)$ represents the position on the free surface. Then the pressure at free surface is represented by

$$
P\left[x, y, z_{S}(x, y)\right]=P_{0}
$$

and Eq. (13) reduces to

$$
A_{x}\left(x-x_{0}\right)+A_{y}\left(y-y_{0}\right)+A_{z}\left(z-z_{0}\right)=0
$$

When the rectangular tank is uniformly accelerated along the x-direction, initially the free surface would slosh back and forth, after some time this motion would disappear and movement would be uniform. The position of the free surface of liquid in a uniformly accelerated tank is shown in Fig. 1.

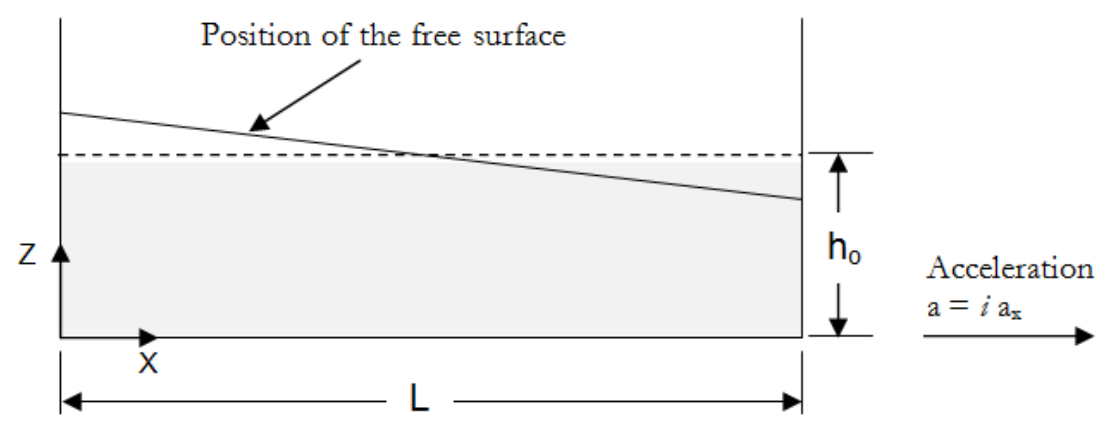

Fig. 1. An accelerated tank.

When the tank is subjected to uniformly accelerated motion along $X$ axis, the acceleration of liquid along the $\mathrm{X}, \mathrm{Y}$ and $\mathrm{Z}$ axes can be expressed as $\quad A_{\mathrm{x}}=-\mathrm{a}_{\mathrm{x}}, \quad \mathrm{A}_{\mathrm{y}}=0 \quad$ and $\quad A_{\mathrm{z}}=-\mathrm{g}$.

Now Eq. (15) becomes

$$
-a_{x}\left(x-x_{0}\right)-g\left(z_{s}-z_{0}\right)=0
$$

Rearranging Eq. (16):

$$
Z_{s}=Z_{0}-\frac{a_{x}}{g}\left(x-x_{o}\right)
$$

To locate the position of interface between two fluids, the principle of conservation of mass can be used, i.e., the mass of the fluid in the tank remains constant.

$$
\begin{gathered}
h_{0} L=\int_{0}^{L} Z_{s} d x \\
h_{0} L=\int_{0}^{L}\left[Z_{0}-\frac{a_{x}}{g}\left(x-x_{0}\right)\right] d x \\
Z_{0}=h_{0}+\frac{a_{x}}{g}\left(\frac{L}{2}-x_{0}\right)
\end{gathered}
$$

Substituting the value of $z_{0}$ into Eq. (17)

$$
Z_{s}=h_{0}+\frac{a_{x}}{g}\left(\frac{L}{2}-x\right)
$$


where $Z_{s}$ is the free surface height of liquid from the bottom of tank.

Equation (21) predicts the position of free surface of liquid in rectangular tank when the tank is subjected to constant acceleration along $\mathrm{X}$ axis. This is used to understand the elevation of liquid surface during motion of the tank. Being a simplified version of Eq. (1) to (4), Eq. (21) cannot be applied to actual tank which are not rectangular in shape. This model can be applied to shapes that are not rectangular by discretizing the domain using numerical techniques. In our work the motion of liquid in actual tank is addressed using ANSYS FLUENT solver wherein discretization of governing equation is achieved.

\section{Numerical Implementation}

Liquid sloshing analysis in a partially filled tank is a multiphase flow problem. In this work, the commercial package ANSYS FLUENT 12.1 is used for developing fluid-structure interaction models. The surface tension and phase change effects are neglected. The governing equations which describe the sloshing behaviour of liquid are continuity Eq. (1) and momentum Eq. (2). For the multiphase flow problem, Volume of Fluid technique is used to track the interface of the liquid and air by solving the continuity Eq. (1). Volume fractions represent the space occupied by each phase, i.e. liquid and air [22]. The volume fraction equation of the secondary phase is given by Eq. (22):

$$
\frac{\partial u}{\partial t}+\nabla \cdot(\alpha u)=0
$$

where $\alpha$ is the volume fraction, $\alpha=1$ for liquid and $\alpha=0$ for air.

The primary phase volume fraction is determined based on the constraint expressed in Eq. (23)

$$
\sum_{i=1}^{2} \alpha_{i}=1
$$

where $\alpha_{i}=$ volume fraction of $i^{\text {th }}$ phase.

In this analysis, air is taken as primary phase and water is taken as secondary phase. The explicit time discretization scheme is employed to solve the volume fraction equation. In a two phase problem, if the phases are represented by the subscripts 1 and 2 , the density in each cell is calculated by [22].

$$
\rho=\alpha_{2} \rho_{2}+\left(1-\alpha_{2}\right) \rho_{1}
$$

For numerical stability and better accuracy of solution, the time step is determined by the CourantFriedrichs-Lewy (CFL) condition. Courant number is defined as

$$
C=u \frac{\Delta t}{\Delta x}
$$

where $\mathrm{C}$ is the courant number, $\Delta \mathrm{t}$ is the time step, $\Delta \mathrm{x}$ is the grid length and $u$ is the velocity fluid at cell. For numerical stability and better accuracy of solution, the time step is selected such that CFL number is less than 1.

The tank structure is considered as a rigid wall and no-slip condition is applied at the liquid-wall interface so that the fluid sticks to the wall and moves with the same velocity of wall.

$$
u=u_{s}
$$

where $u_{s}=$ structural velocity, $u=$ fluid velocity

\section{Experimental studies}

\section{1. $\quad 4.1$ Experimental Setup}

The experimental setup consists of transparent automotive fuel tank, high speed camera with computer interface, mounting table, and counterweight. The fuel tank is fabricated using glass fibre and epoxy resin. The top and side walls of the fuel tank are made of acrylic sheet for better visibility. The spatial dimensions of the tank are 568 X 370 X $140 \mathrm{~mm}$ respectively. The fabricated transparent fuel tank is shown in Fig. 2(a). The positions of baffles and dimensions of the tank are shown in Figs. 2(b) and 2(c). 


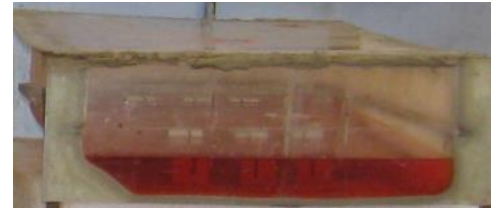

a) Fuel tank

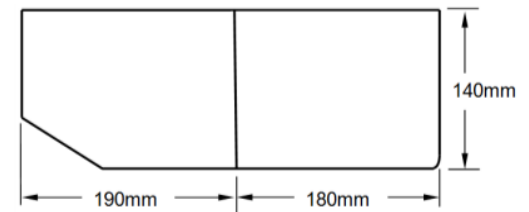

b) Position of single baffle

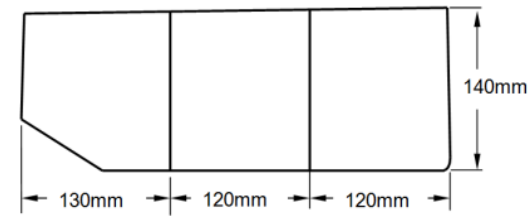

c) Position of two baffles

Fig. 2. Position of baffles.

Figure 3 shows the experimental set up used for sloshing analysis. To improve the visibility of liquid in the tank a colouring agent is added with the water. The experimental studies are carried out for different fill levels such as $25 \%, 50 \%$ and $60 \%$ of the tank height.

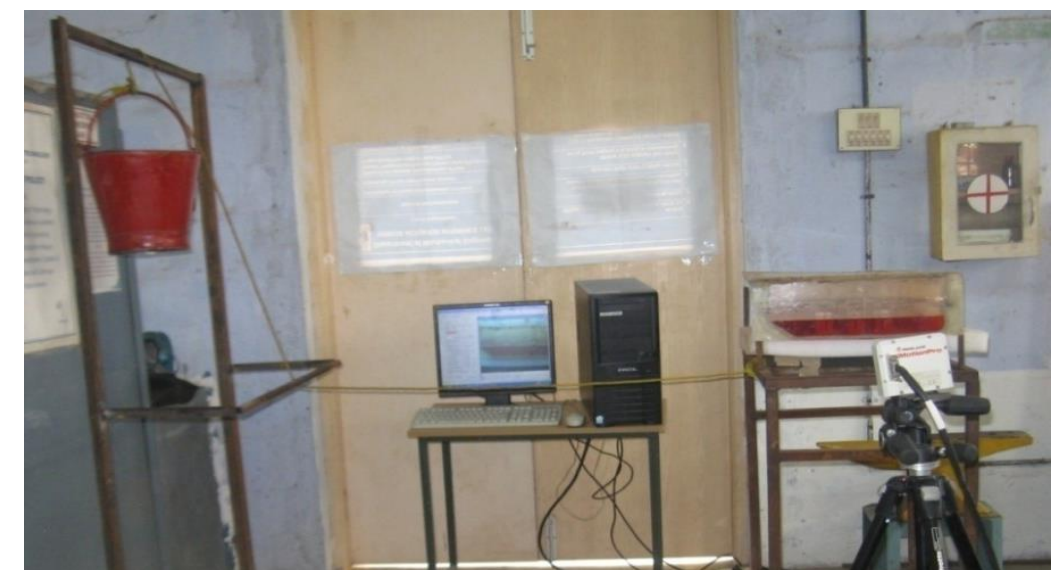

Fig. 3. Experimental set up.

To study the influence of baffles on free surface elevation, experiments are conducted for three cases, (i) without baffles, (ii) with one vertical baffle and (iii) with two vertical baffles. The tank is mounted on the roller table which is driven by a rope attached to a counterweight suspended at a height of $2 \mathrm{~m}$. A uniformly accelerated motion is applied to the tank by suddenly releasing the counterweight. The free surface motion of the liquid is captured using a high speed camera, Redlake's MotionPro10000 with 50mm, 1:1.4D lens. This camera is capable of acquiring images up to 10,000 frames per second (fps) at the maximum resolution of $1280 \times 1024$ pixels.

\subsection{Similitude Relations for Translational Motion}

The non-dimensional variables for study of liquid sloshing in the automotive fuel tank are developed based on similitude theory. For free surface flow, the Reynolds number and Froude number are to be kept constant. According to Buckingham Pi Theorem, the dimensionless products can be written as

$$
\Pi_{1}=\varphi\left(\Pi_{2}, \Pi_{3}, \Pi_{4}, \ldots \ldots \ldots \Pi_{n-m}\right)
$$

where $\mathrm{n}=$ number of variables and $\mathrm{m}=$ number of reference dimensions required to define the variable.

Norman Abramson et al. [23] applied similitude theory to the problem of fuel sloshing and similitude relations for free surface flow are expressed as

$$
\frac{F t^{2}}{\rho l^{4}}=\varphi\left(\frac{a t^{2}}{l}, \frac{h}{l}, \frac{x}{l}, \frac{\rho l^{2}}{\mu t}\right)
$$

where $F=$ resultant liquid force on tank wall in Newton's $(\mathrm{N}), \mathrm{t}=$ time period in seconds $(\mathrm{s}), \mathrm{l}=\operatorname{tank}$ length in meter $(\mathrm{m}), \mathrm{x}=$ excitation amplitude in meter $(\mathrm{m}), \rho=$ liquid density $\left(\mathrm{kg} / \mathrm{m}^{3}\right), \mathrm{a}=$ linear acceleration acting on tank $\left(\mathrm{m} / \mathrm{s}^{2}\right), \mu=$ dynamic viscosity $\left(\mathrm{Ns} / \mathrm{m}^{2}\right), \mathrm{h}=$ free surface height in meter $(\mathrm{m})$.

From Eq. (28) the non-dimensional time $\left(\mathrm{T}^{*}\right)$ and free surface height $\left(\mathrm{H}^{*}\right)$ can be represented by

$$
T^{*}=t \sqrt{\frac{a}{l}} \quad \text { and } H^{*}=\frac{h}{l}
$$


By considering $\Pi$ term equivalent to Reynolds number and Froude number similitude relations can be written as

$$
\frac{l_{m}}{l_{p}}=\left(\frac{v_{m}}{v_{p}}\right)^{\frac{2}{3}}\left(\frac{a_{p}}{a_{m}}\right)^{\frac{1}{2}}
$$

where $v$ is the kinematic viscosity, subscript $m$ represents the model and $p$ represents the prototype.

Vuk Bogdanovic et al. [24] experimentally measured the vehicle accelerations at signalized intersections and reported that over $95 \%$ of the vehicle accelerations are in the interval of $0.71-3.40 \mathrm{~m} / \mathrm{s}^{2}$. In this work liquid sloshing behaviours are analysed for an average acceleration of $2.45 \mathrm{~m} / \mathrm{s}^{2}$. Based on similarity relationships, mentioned in Eq. (29), scaling parameters for acceleration is selected. The liquid properties and linear acceleration specified in this analysis are presented in Table 1. The experiments are conducted on model that is developed using similitude principles.

Table 1. Parameters of model for sloshing analysis.

\begin{tabular}{clcc}
\hline S. No. & \multicolumn{1}{c}{ Parameter } & Actual Fuel Tank & Experiment \& Numerical Analysis \\
\hline $\mathbf{1}$ & Liquid & Gasoline & Water \\
$\mathbf{2}$ & Tank Length $(\mathrm{m})$ & 0.37 & 0.37 \\
$\mathbf{3}$ & Kinematic Viscosity $\left(\mathrm{m}^{2} / \mathrm{s}\right)$ & $10^{-6}$ & $8.11 \times 10^{-7}$ \\
$\mathbf{4}$ & Acceleration $\left(\mathrm{m} / \mathrm{s}^{2}\right)$ & 2.45 & 1.6 \\
\hline
\end{tabular}

\section{Results and Discussions}

The sloshing behaviour of the liquid in the automotive fuel tank, with and without baffles, is studied numerically and experimentally. In numerical simulation, the tank is subjected to a translational motion with constant acceleration of $1.6 \mathrm{~m} / \mathrm{s}^{2}$ along its transverse axis and influence of baffles and liquid levels on the free surface elevation of the liquid (h) from the bottom of the tank is predicted. In the experimental study, the same acceleration is applied to the tank by suddenly releasing the weight from the height of $2 \mathrm{~m}$ and the free surface profiles are captured using high speed camera.

\section{1. $\quad$ Effect of Fill Level on Liquid Sloshing}

To study the effect of fill level on free surface elevation, the experiments are conducted with $25 \%, 50 \%$ and $60 \%$ fill levels of the tank. The free surface elevations are also predicted numerically for same fill levels. Figures 4(a) to 4(f) compare the snapshots of free surface profiles of liquid when the free surface reaches the maximum height at the right wall. The free surface profiles predicted by the numerical model agree with that of the experimental results. The software simulations show that the time taken for the free surface to reach the maximum height is marginally reduced from $0.5 \mathrm{sec}$ to $0.42 \mathrm{sec}$ when the liquid level is increased from $25 \%$ to $60 \%$ of the tank height. The results obtained from the simulations are supported by experimental results. 


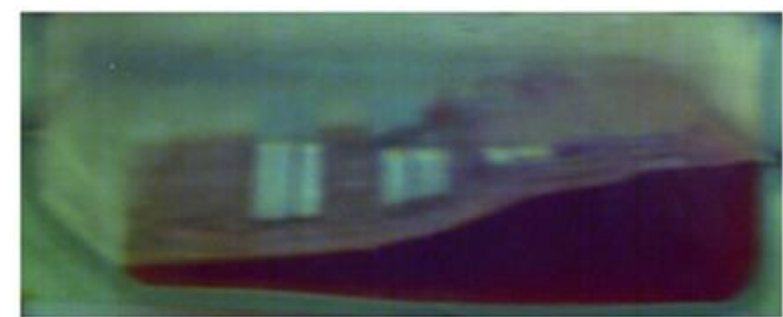

a) $25 \%$ fill level at $0.5 \mathrm{Sec}$

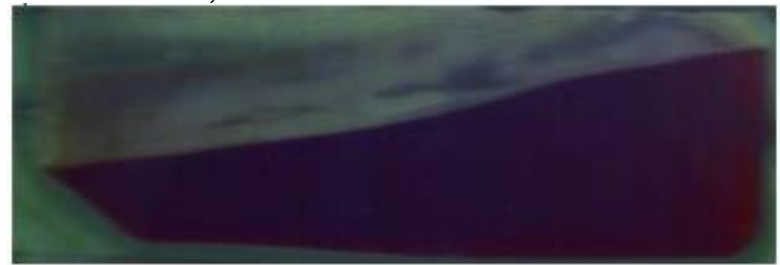

b) $50 \%$ fill level at $0.44 \mathrm{Sec}$

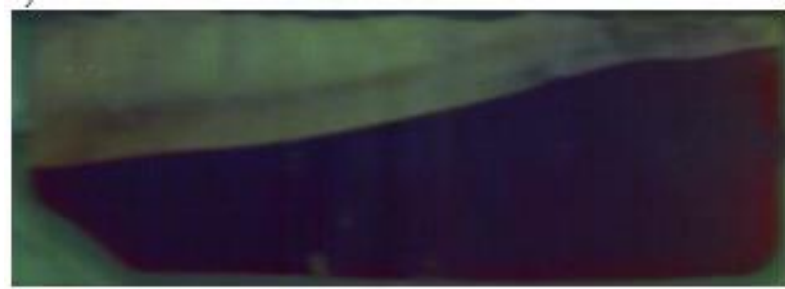

c) $60 \%$ fill level at $0.42 \mathrm{Sec}$

(i) Experimental results

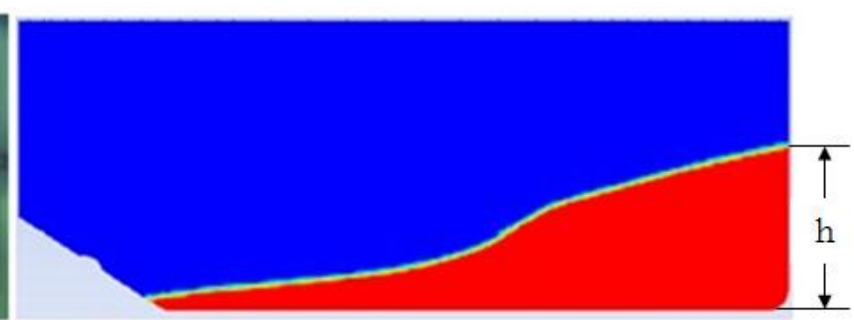

d)

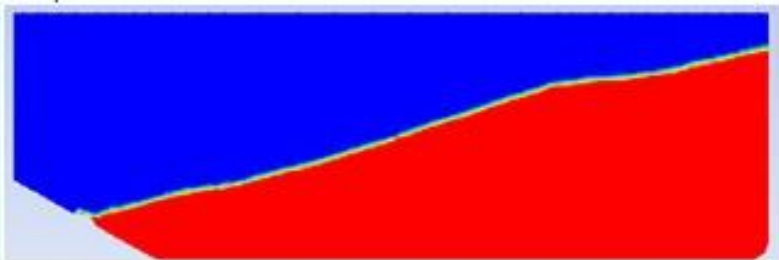

e)

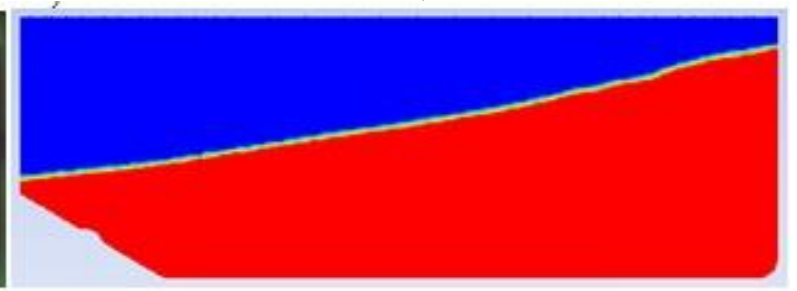

f)

(ii) Numerical results

Fig. 4. Comparison of free surface profiles in unbaffled tank when the free surface reaches maximum height at the right wall

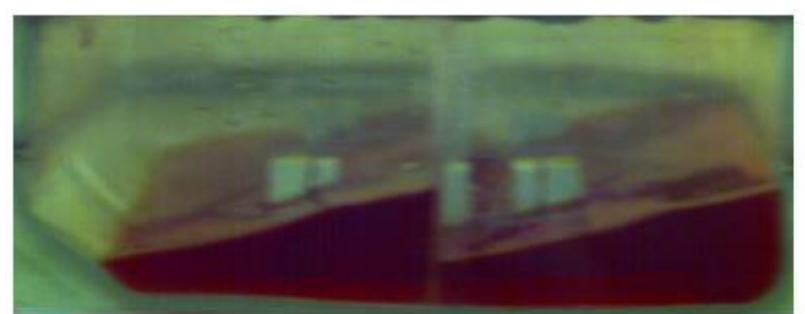

a) $25 \%$ fill level at $0.32 \mathrm{sec}$

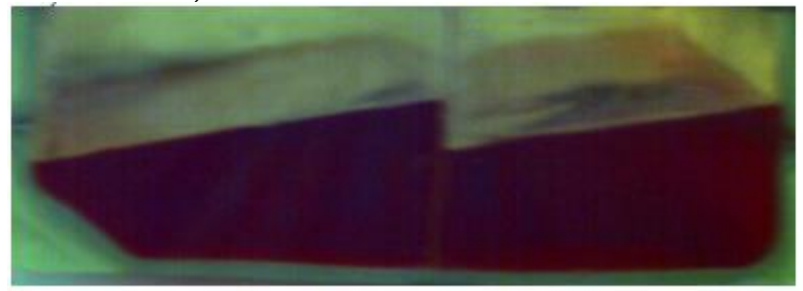

b) $50 \%$ fill level at $0.24 \mathrm{Sec}$

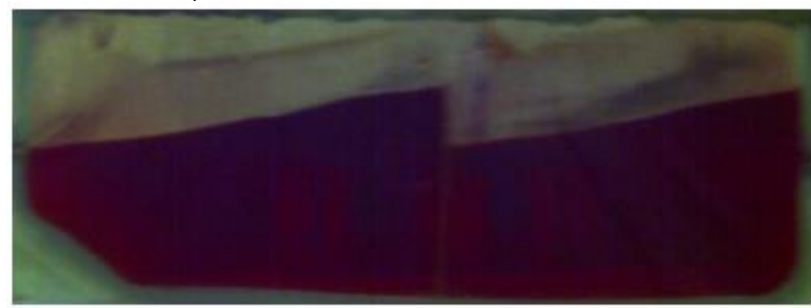

c) $60 \%$ fill level at $0.2 \mathrm{Sec}$

(i) Experimental results

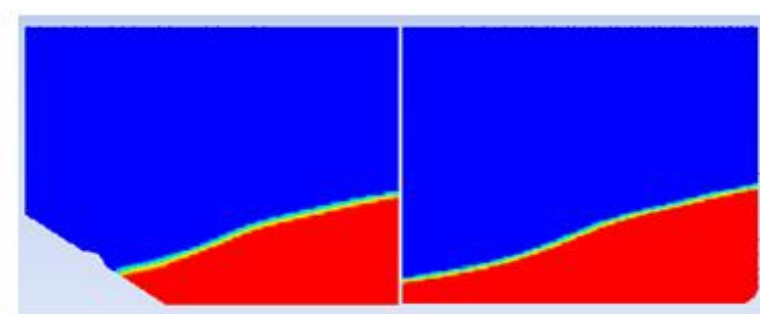

d)

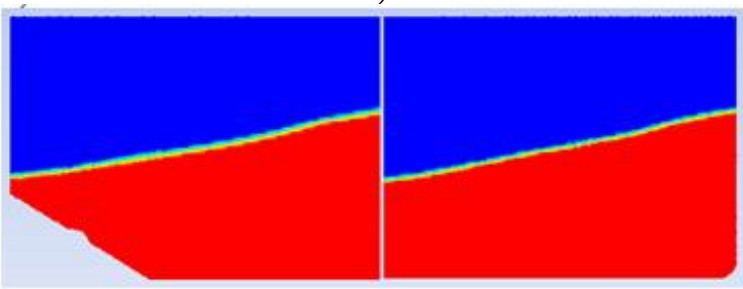

e)

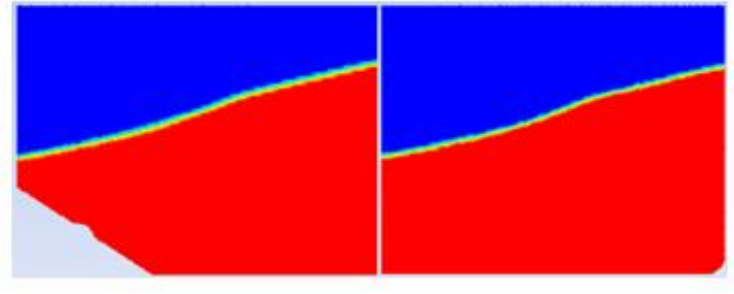

f)

(ii) Numerical results

Fig. 5. Comparison of free surface profiles in single baffled tank when the free surface reaches maximum height at the right wall. 


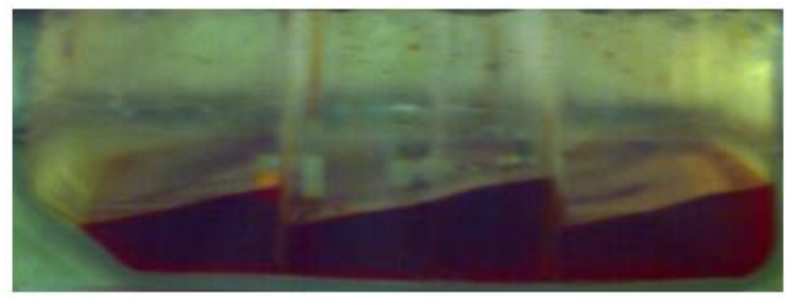

a) $25 \%$ fill level at $0.22 \mathrm{Sec}$

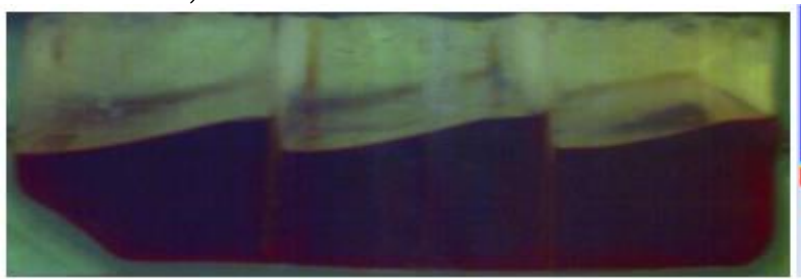

b) $50 \%$ fill level at $0.18 \mathrm{Sec}$

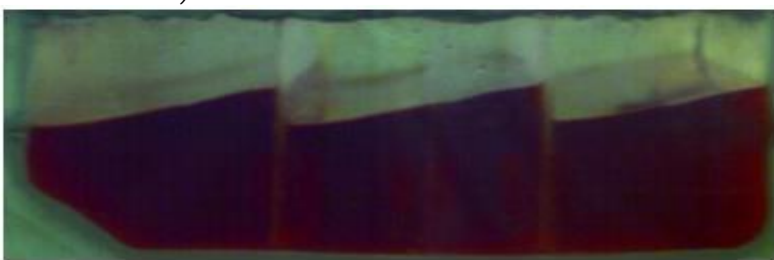

c) $60 \%$ fill level at $0.18 \mathrm{Sec}$

(i) Experimental results
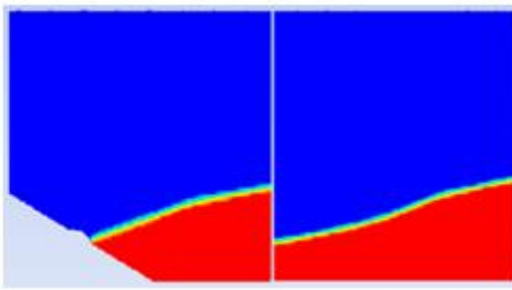

d)

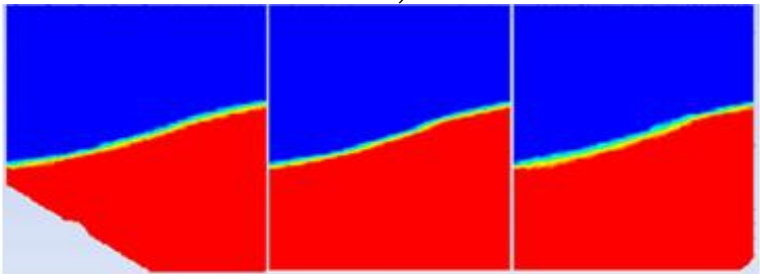

e)
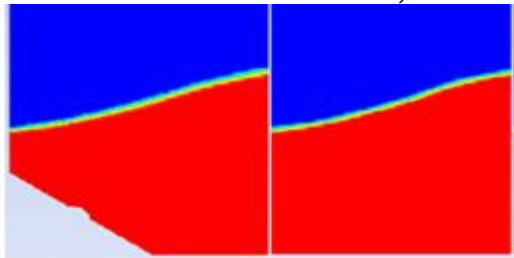

f)

(ii) Numerical results

Fig. 6. Comparison of free surface profiles in double baffled tank when the free surface reaches maximum height at the right wall.

Figures 5 and 6 present the comparison of free surface profiles of liquid in a single and double baffled tank when the free surface reaches the maximum height at the right wall. Figures 5(a) to 5(f) compare the snapshots of free surface profiles obtained from experimental study with numerical analysis for $25 \%, 50 \%$ and $60 \%$ filled tank with single baffle. In single baffled tank, the time taken for the free surface to reach the maximum height is reduced from $0.32 \mathrm{sec}$ to $0.2 \mathrm{sec}$ when the liquid level is increased from $25 \%$ to $60 \%$ of the tank height, Similarly, Figs. 6(a) to 6(f) compare the snapshots of free surface profiles obtained from experimental and numerical analysis for $25 \%, 50 \%$ and $60 \%$ filled tank with double baffles. In this case, the time taken for the free surface to reach the maximum height is reduced from $0.22 \mathrm{sec}$ to 0.18 sec when the liquid level is increased from $25 \%$ to $60 \%$ of the tank height,

In all the three cases, that is (i) tank without baffle (WOB), (ii) tank with single baffle (SB) and (iii) tank with double baffles (DB), it is observed that the time taken for the free surface to reach the maximum height and magnitude of free surface oscillation are reduced when the liquid level is increased, this is due to the change in sloshing frequencies of the free surface waves.

D. V. Evans and P. Mciver [25] indicated the natural frequency of free surface wave $\left(\omega_{n}\right)$ as

$$
\omega_{n}^{2}=g k \cdot \tanh (k h)
$$

where $k=\frac{n \pi}{l} ; \mathrm{n}=1,2, \ldots$, and $\mathrm{l}=$ tank length and $\mathrm{h}=$ liquid level.

From Eq. (30) it is clear that, liquid level highly influences the natural frequency of the free surface wave; hence the time taken for the free surface to reach the maximum height is reduced as the liquid level is increased.

To validate the result obtained from numerical simulations, experiments are carried out for various liquid levels and free surface profiles are captured using high speed camera for the time period of $1 \mathrm{sec}$. The free surface height at the right wall is measured using the captured image with help of ImageJ, a Java-based image processing program. Figures 7,8 and 9 illustrate the time-histories of free surface height at the right wall of the unbaffled and baffled tank with $25 \%, 50 \%$ and $60 \%$ liquid level. In this graph, the variables time $\left(\mathrm{T}^{*}\right)$ and free surface height $\left(\mathrm{H}^{*}\right)$ are non-dimensionalised using the similitude relations expressed in 
Eq. (28). It is observed that an amplitude free surface elevation obtained from numerical analysis deviates maximum of $14 \%$ (sometimes lower also) from the experimental results. These deviations are due to turbulence effects of liquid which are not included in the numerical analysis.

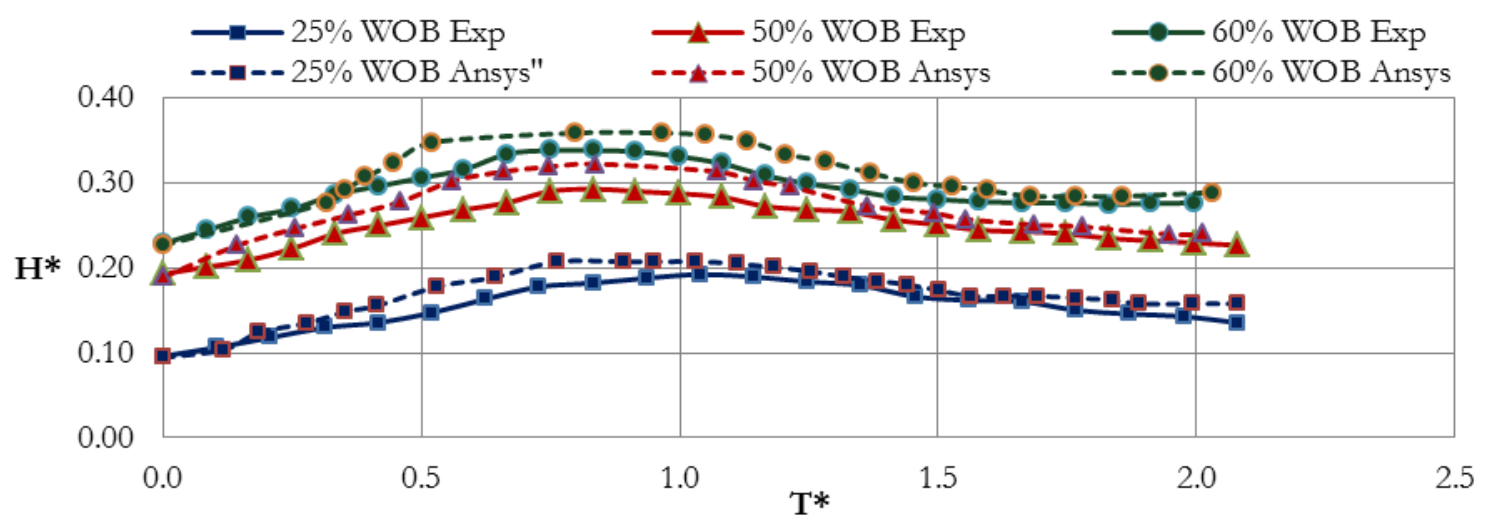

Fig. 7. Free surface elevation at the right wall in unbaffled tank.

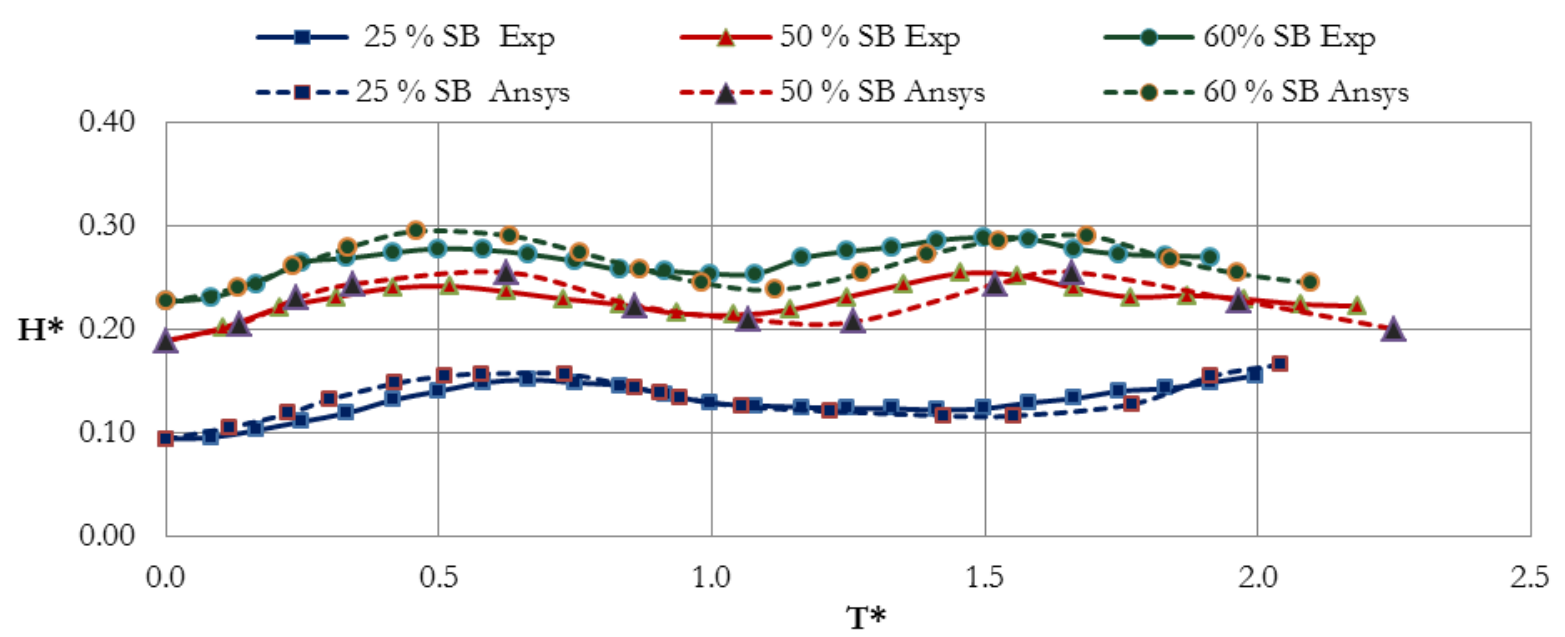

Fig. 8. Free surface elevation at the right wall in single baffled tank.

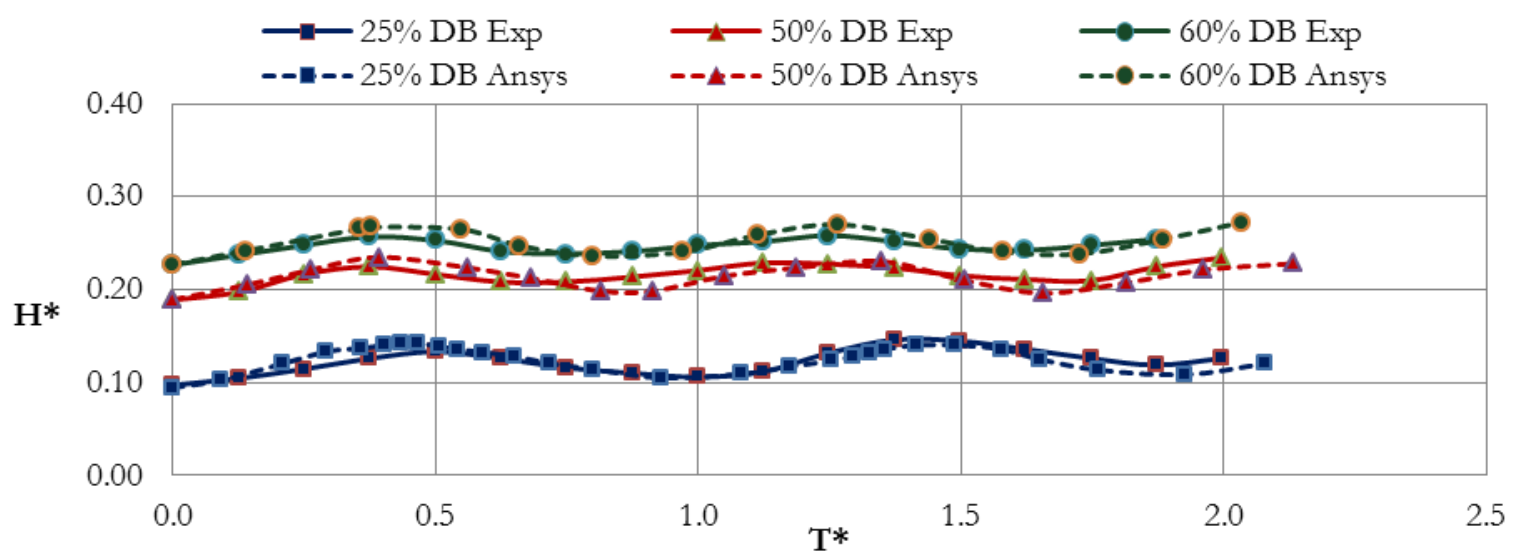

Fig. 9. Free surface elevation at the right wall in double baffled tank.

When the tank is accelerated from the rest, liquid experiences a jerky motion initially so that the free surface moves back and forth but over the period of time this oscillation vanishes and free surface stays at a stable position. To predict final position of free surface, numerical simulations are performed up to 4 seconds. Figure 10 shows the time histories of free surface elevation for $25 \%, 50 \%$ and $60 \%$ liquid level of single baffled tank. Increasing fill level reduces the magnitude of free surface height and it quickly reaches 
the stable position. This is due the increase in liquid mass which absorbs the sudden disturbances applied to the tank. The positions of free surface at the end of 4 seconds are shown in Fig. 11(a) to 11(i).

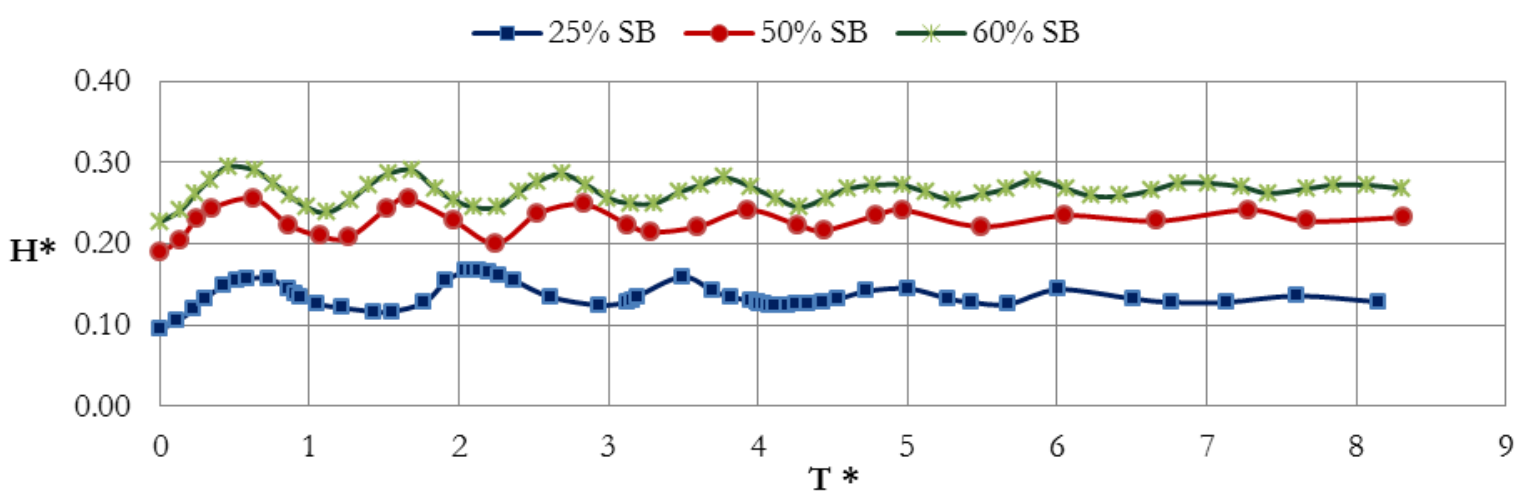

Fig. 10. Free surface elevation at the right wall of single baffled tank.

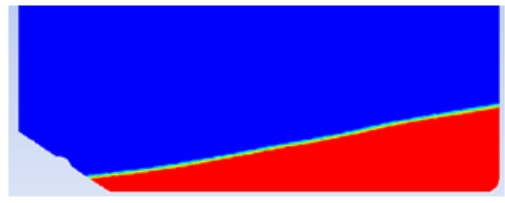

a) $25 \%$ fill level at $4 \mathrm{sec}$

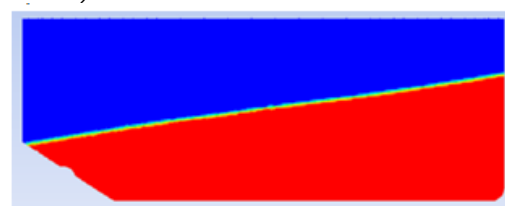

b) $50 \%$ fill level at $4 \mathrm{sec}$

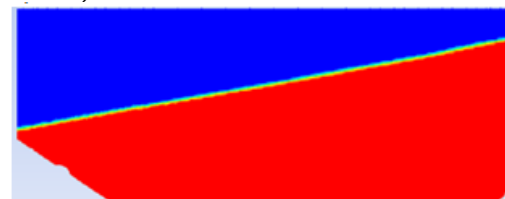

c) $60 \%$ fill level at $4 \mathrm{sec}$

(i) Tank without baffle

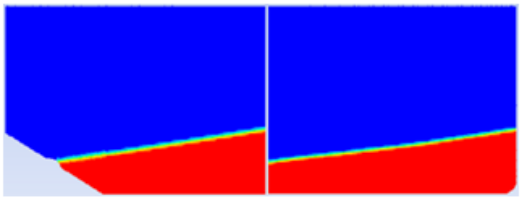

d)

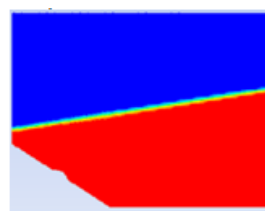

e)

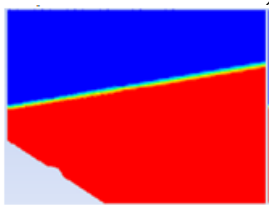

(ii) Tank with single baffle
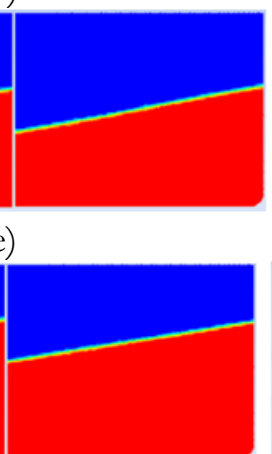

f)

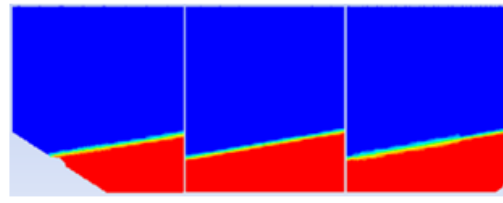

g)

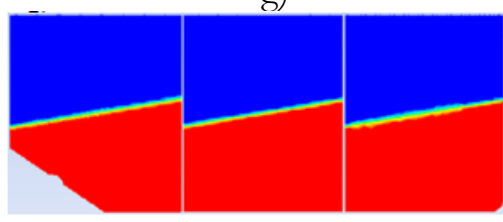

h)

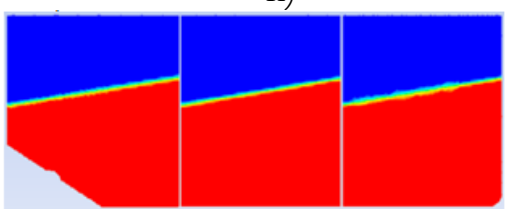

i)

Fig. 11. Comparison of free surface profiles in unbaffled, single and double baffled tank at 4 sec.

The slope of this free surface depends upon the magnitude of acceleration and characteristic length of the tank. The position of free surface along the length of the rectangular tank can be calculated using Eq. (21). Figures 12, 13 and 14 compare the position of the free surface of liquid in $25 \%, 50 \%$ and $65 \%$ filled, baffled and unbaffled, tank predicted by the numerical analysis at the end of 4 seconds and analytical results obtained for rectangular tank.

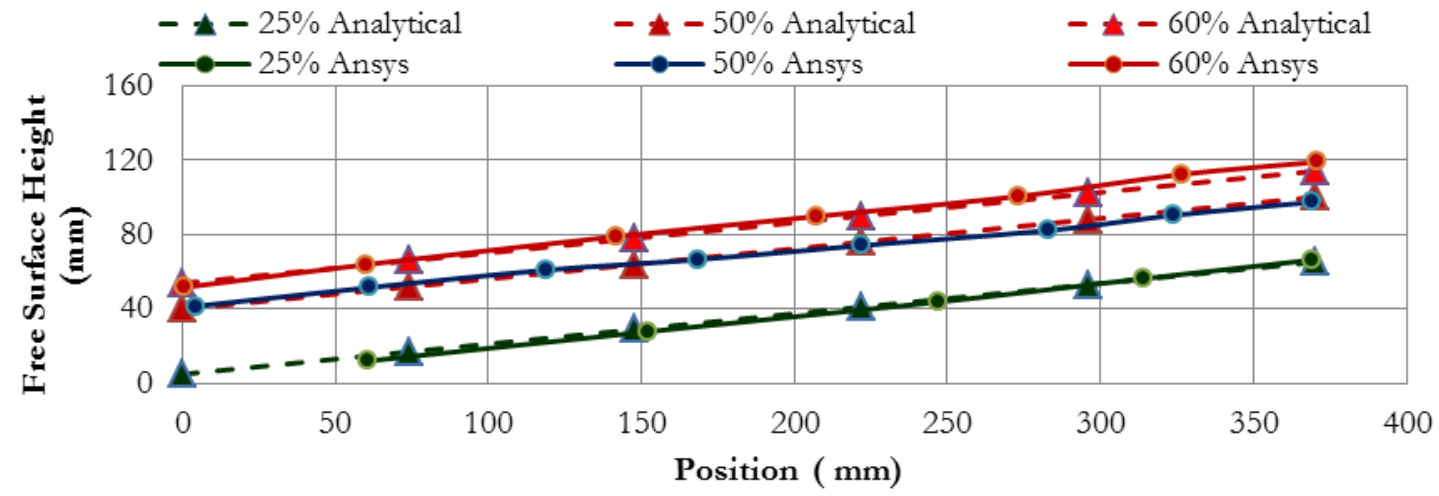

Fig. 12. Position of the free surface of liquid in unbaffled tank. 


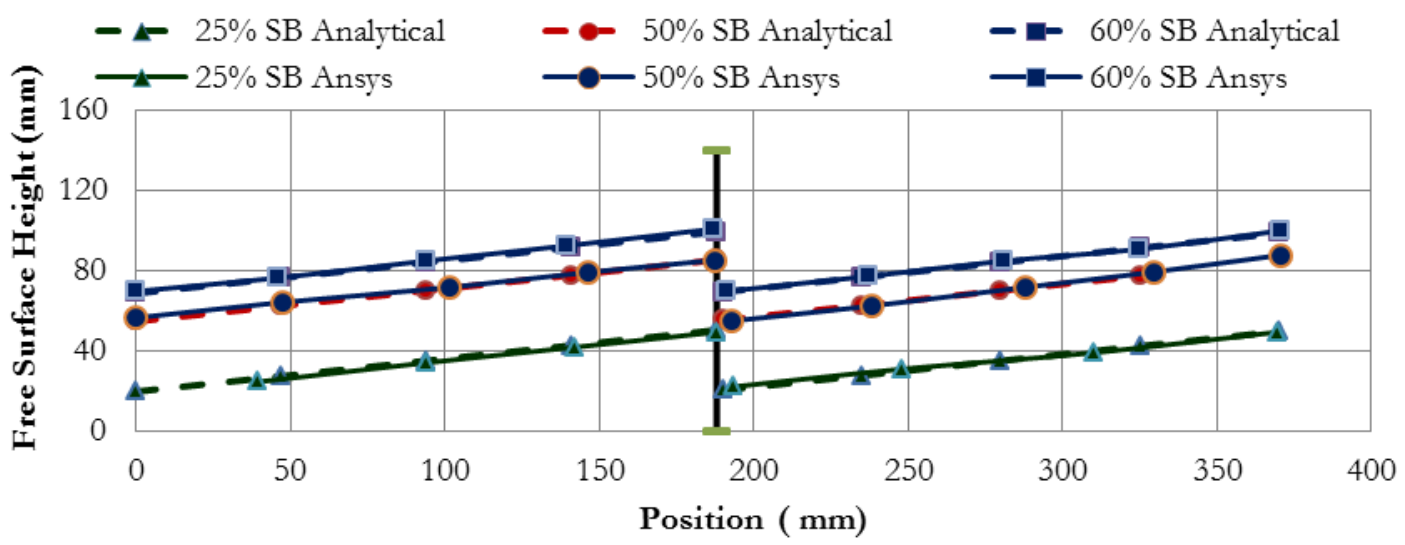

Fig. 13. Position of the free surface of liquid in single baffled tank.

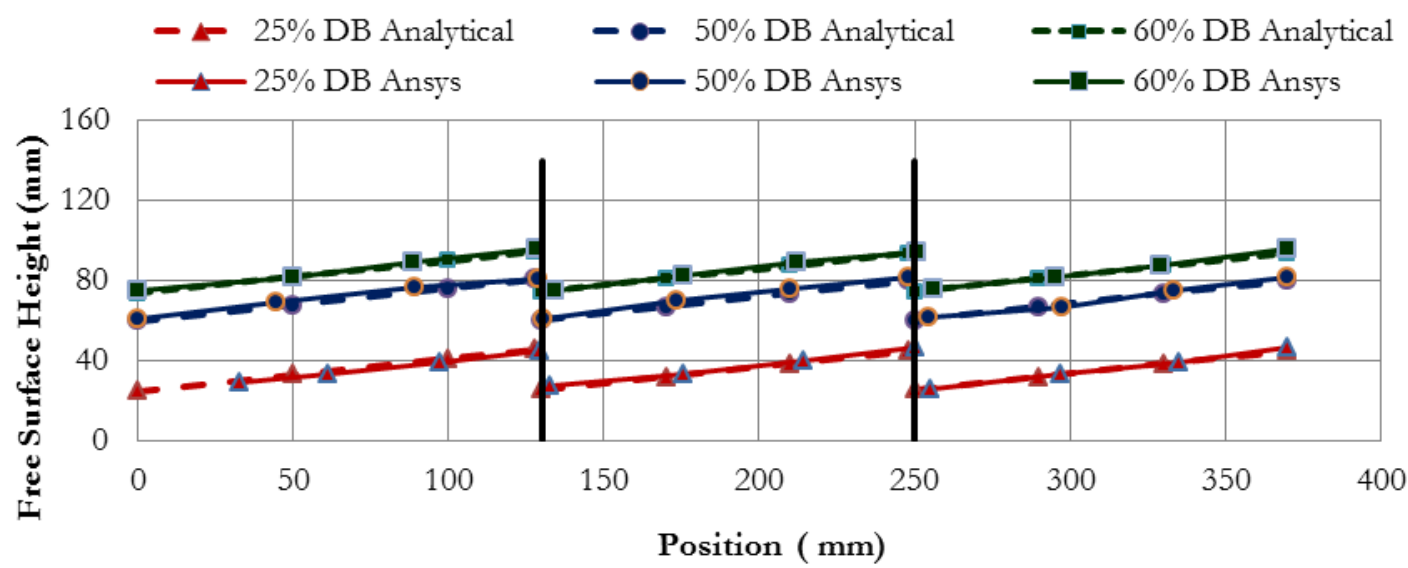

Fig. 14. Position of the free surface of liquid in double baffled tank.

It is noticed that, the slope of the free surface is same for all the liquid levels but introduction of baffles decreases the characteristics length of tank as a result slope of free surface is reduced. In this case, the free surface elevation obtained from the numerical analysis deviates maximum of $5 \%$ from the analytical solution obtained for the rectangular tank.

\subsection{Effect of Baffles on Liquid Sloshing}

Reducing the sloshing effect in partially filled containers is a major concern in the design of liquid storage containers and fuel tank. One method to reduce the liquid sloshing in a partially-filled tank is by using baffles for energy dissipation. The baffles absorb the kinetic energy of the liquid and suppress the wave motion. In this work, the vertical baffles are placed in the tank as shown in Figs. 2(b) \& 2(c) and the influence of baffles on free surface elevations are analysed.

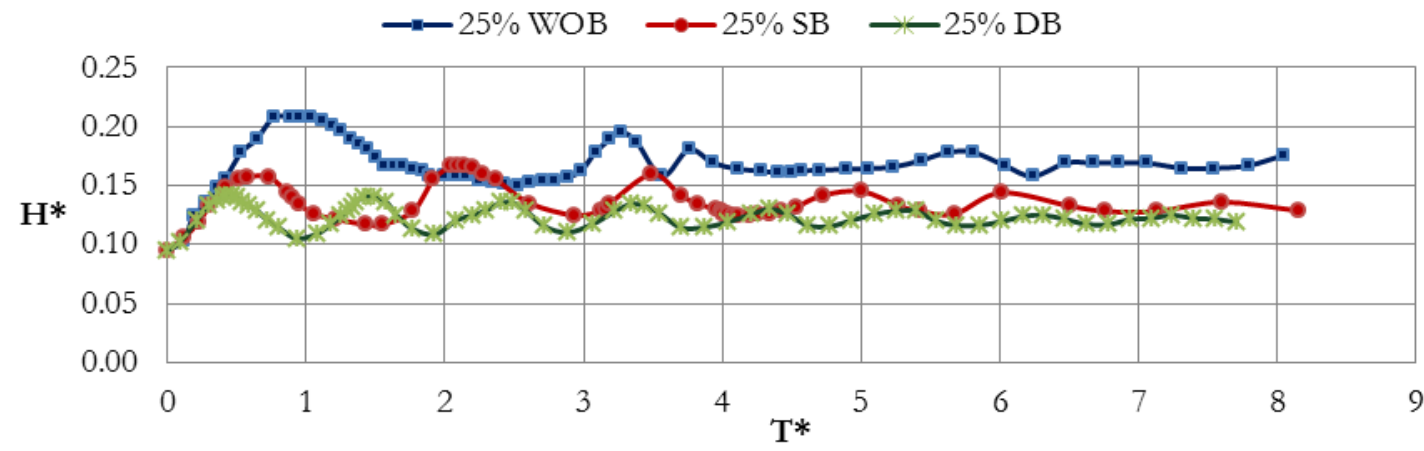

Fig. 15. Comparison of the amplitude of free surface elevation at the right wall of $25 \%$ filled baffled and unbaffled tank. 
Figure 15 presents the time histories of non-dimensional free surface height $\left(\mathrm{H}^{*}\right)$ for $25 \%$ filled baffled and unbaffled tank. The free surface wave reaches the maximum non-dimensionalised height $\left(\mathrm{H}^{*}\right)$ of 0.208 , 0.157 and 0.142 in unbaffled, single baffled and double baffled tank respectively.

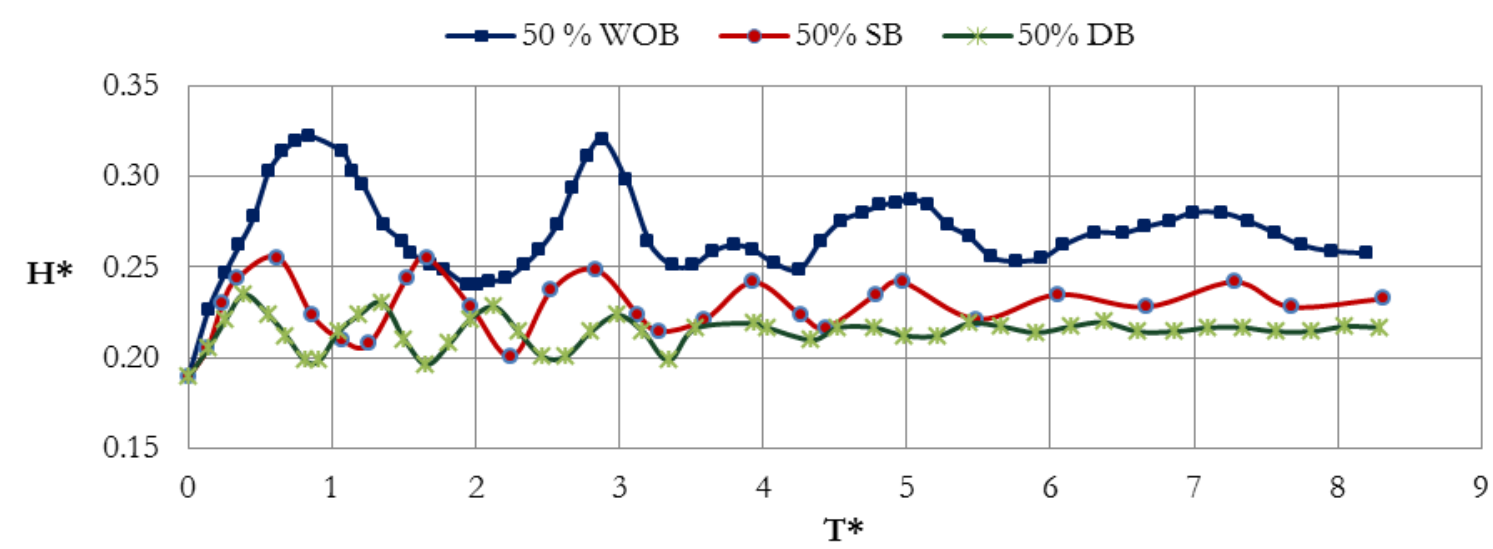

Fig. 16. Comparison of the amplitude of free surface elevation at the right wall of $50 \%$ filled baffled and unbaffled tank.

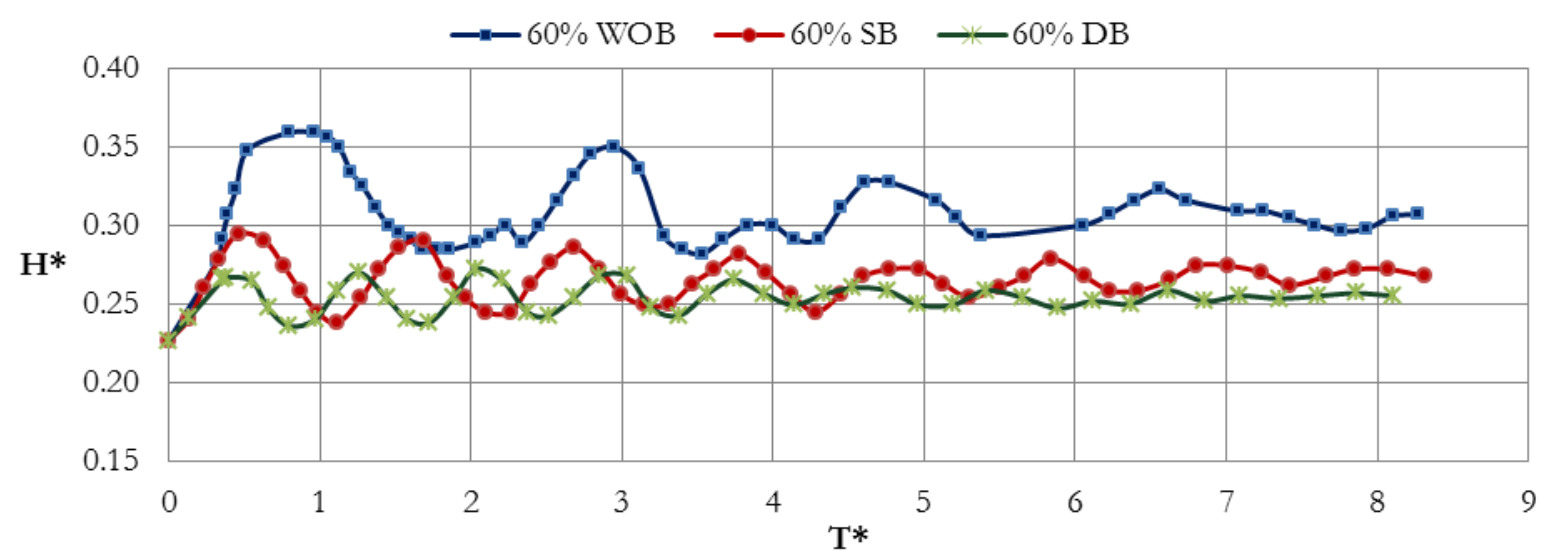

Fig. 17. Comparison of the amplitude of free surface elevation at the right wall of $60 \%$ filled baffled and unbaffled tank.

Figures 16 and 17 illustrate the behaviour of free surface waves in $50 \%$ and $60 \%$ filled baffled and unbaffled tanks. In 50\% filled tank, the non-dimensionalised height $\left(\mathrm{H}^{*}\right)$ of free surface (maximum ) are $0.323,0.255$ and 0.235 in unbaffled, single baffled and double baffled tank respectively. In $60 \%$ filled tank, the non-dimensionalised height $\left(\mathrm{H}^{*}\right)$ of free surface (maximum) are $0.359,0.295$ and 0.267 in unbaffled, single baffled and double baffled tank respectively. From the numerical simulation it is observed that, placing of vertical baffles along the longitudinal axis of the tank significantly reduces the amplitude of free surface displacement. When the baffles are placed, it separates the tank into small compartments thus reduces the characteristic length of the tank and also absorb the kinetic energy of the liquid.

\section{Conclusions}

In this study, the influence of fill levels and baffles on the sloshing phenomena in automotive fuel tank are numerically analysed and results are supported with analytical solution and experimental results. The fuel tank is subjected to uniform acceleration and the free surface elevations of liquid are simulated using ANSYS FLUENT software. The Volume of Fluid technique is used for tracking the free surface motion of liquid. To validate the results obtained from numerical simulations, experiments are carried out using transparent fuel tank filled with colored water and the free surface profiles are captured for time period of 1 second using high speed camera interfaced with computer. These experiments are conducted on model that 
is constructed using similitude principles. An analytical model is also developed for rectangular tank to find position of the free surface along the tank length. The results obtained from the numerical analysis are compared with experimental results. From the analysis, it is noticed that the amplitude of free surface elevation of liquid obtained from numerical model deviates maximum of $14 \%$ from the experimental results.

The numerical simulation indicates that when the fill level is increased, there is a marginal decrease in amplitude of liquid free surface displacement. The increase of liquid mass absorbs the disturbance applied to the tank and thereby helps the free surface to quickly reach the stable condition. The baffles reduce the characteristic length of the tank and restrict the motion of free surface waves which subsequently reduces the amplitude of free surface motion. The numerical model which has been developed in this work can be further extended to study the various excitation conditions, tank geometry and baffle configurations.

\section{Acknowledgements}

The authors express their gratitude to the Management and Principal, PSG College of Technology, Coimbatore, for providing necessary infrastructure and facilities to complete this work.

\section{References}

[1] M. S. Celebi and H. Akyildiz, "Nonlinear modeling of liquid sloshing in a moving rectangular tank," Ocean Eng., vol. 29, no. 12, pp. 1527-1553, 2002.

[2] F. H. Harlow and J. E. Welch, "Numerical calculation of time-dependent viscous incompressible flow of fluid with free surface," Phys. Fluids, vol. 8, no. 12, p. 2182, 1965.

[3] C. W. Hirt and B. D. Nichols, "Volume of fluid (VOF) method for the dynamics of free boundaries," J. Comput. Phys., vol. 39, no. 1, pp. 201-225, 1981.

[4] H. Abramson, "The dynamic behavior of liquids in moving containers, with applications to space vehicle technology," Nasa Sp-106, 1966.

[5] R. A. Ibrahim, Liquid Sloshing Dynamics: Theory and Applications. Cambridge University Press, 2005.

[6] T. J. R. Hughes, W. K. Liu, and T. K. Zimmermann, "Lagrangian-Eulerian finite element formulation for incompressible viscous flows," Comput. Methods Appl. Mech. Eng., vol. 29, no. 3, pp. 329-349, 1981.

[7] S. S. Babu and S. Bhattacharyya, "Finite element analysis of fluid-structure interaction effect on liquid retaining structures due to sloshing," Comput. Struct., vol. 59, no. 6, pp. 1165-1171, 1996.

[8] N. Pal, S. Bhattacharyya, and P. Sinha, "Experimental investigation of slosh dynamics of liquid-filled containers," Exp. Mech., vol. 41, no. 1, pp. 63-69, 2001.

[9] N. Aquelet, M. Souli, J. Gabrys, and L. Olovson, "A new ALE formulation for sloshing analysis," Struct. Eng. Mech., vol. 16, no. 4, pp. 423-440, 2003.

[10] D. Liu and P. Lin, "A numerical study of three-dimensional liquid sloshing in tanks," J. Comput. Phys., vol. 227, no. 8, pp. 3921-3939, 2008.

[11] G. Popov, S. Sankar, T. Sankar, and G. Vatistas, "Liquid sloshing in rectangular road containers," Comput. Fluids, vol. 21, no. 4, pp. 551-569, 1992.

[12] S. aus der Wiesche, "Computational slosh dynamics: theory and industrial application," Comput. Mech., vol. 30, no. 5-6, pp. 374-387, 2003.

[13] S. aus der Wiesche, "Noise due to sloshing within automotive fuel tanks," Forsch. Im Ingenieurwesen, vol. 70, no. 1, pp. 13-24, 2005.

[14] C. Wachowski, J. Biermann, and R. Schala, "Approaches to analyse and predict slosh noise of vehicle fuel tanks," presented at the 24th International Conference of Noise and Vibration Engineering (ISMA2010), Belgium, 2010.

[15] M. Eswaran and U. K. Saha, "Experimental investigation for capturing liquid free surface elevation in an externally induced tank," Dev. Appl. Ocean. Eng., vol. 2, no. 1, 2013.

[16] H. Jin, Y. Liu, and H.-J. Li, "Experimental study on sloshing in a tank with an inner horizontal perforated plate," Ocean Eng., vol. 82, pp. 75-84, 2014.

[17] M. Eswaran, U. K. Saha, and D. Maity, "Effect of baffles on a partially filled cubic tank: numerical simulation and experimental validation," Comput. Struct., vol. 87, no. 3, pp. 198-205, 2009.

[18] J. Jung, H. Yoon, C. Lee, and S. Shin, "Effect of the vertical baffle height on the liquid sloshing in a three-dimensional rectangular tank," Ocean Eng., vol. 44, pp. 79-89, 2012. 
[19] C. Koh, M. Luo, M. Gao, and W. Bai, "Modelling of liquid sloshing with constrained floating baffle," Comput. Struct., vol. 122, pp. 270-279, 2013.

[20] S. Nicolici and R. Bilegan, "Fluid structure interaction modeling of liquid sloshing phenomena in flexible tanks," Nucl. Eng. Des., vol. 258, pp. 51-56, 2013.

[21] S. Whitaker, "The differential equations of motion" in Introduction to Fluid Mechanics. Englewood Cliffs, NJ: Prentice-Hall, Inc., 1968, Ch. 5, sec. 5.6, pp. 128-179.

[22] ANSYS FLUENT, Theory Guide, Release 12.0, ANSYS, Inc., 2009.

[23] H. N. Abramson, R. Martin, and G. E. Ransleben Jr., "Application of similitude theory to the problem of fuel sloshing in rigid tanks," DTIC Document, No. SWRI-TR-1, Southwest Research Inst San Antonio, TX, 1958.

[24] V. Bogdanović, N. Ruškić, Z. Papić, and M. Simeunović, "The research of vehicle acceleration at signalized intersections," Promet-Traffictransportation, vol. 25, no. 1, pp. 33-42, 2013.

[25] D. Evans and P. McIver, "Resonant frequencies in a container with a vertical baffle," J. Fluid Mech., vol. 175, pp. 295-307, 1987. 